\title{
High prevalence of diabetes in young people in Bangalore, India
}

\author{
SATYAN M RAJBHANDARII, ${ }^{1,2}$ K VIJAY KUMAR, ${ }^{2}$ RAJA SELVARAJAN, ${ }^{2}$ TARA MURALI ${ }^{2}$
}

\begin{abstract}
Background and aims: The burden of diabetes in India is increasing, especially in cities. We conducted a crosssectional survey of the prevalence of diabetes and a measure of prediabetes in an urban population in Bangalore, India. Methods: Screening was conducted free of charge and without need for a prior appointment in 32 screening sites throughout Bangalore. Diabetes was defined either on the basis of a self-reported prior diagnosis or as undiagnosed diabetes on the basis of a random blood glucose measurement of $>11.1 \mathrm{mmol} / \mathrm{L}$ ( $200 \mathrm{mg} / \mathrm{dL})$. A second index of dysglycaemia, termed prediabetes, was defined as a random blood glucose measurement of $>7.8 \mathrm{mmol} / \mathrm{L}(140 \mathrm{mg} / \mathrm{dL})$ but less than $11.1 \mathrm{mmol} / \mathrm{L}$.

Results: The study population comprised 3,691 subjects, screened over a period of 15 months. Previously diagnosed diabetes was present in 818 patients $(22.2 \%)$, previously undiagnosed diabetes in 67 patients $(1.8 \%)$ and the additional measure of prediabetes in 221 patients (6\%). Accordingly, almost one-third of subjects $(30 \%)$ had diabetes or prediabetes by our criteria. Diabetes (diagnosed or undiagnosed) and prediabetes were more common in older subjects than younger subjects, as would be expected.

Conclusions: We observed high rates of dysglycaemia in a large urban population in Bangalore. Our data add to previous reports of a substantial burden of abnormal glucose regulation in this setting. Additional public health initiatives are required to protect the citizens of Bangalore from diabetes and its future complications.

Br J Diabetes 2020;20:104-106
\end{abstract}

Key words: type 2 diabetes, prevalence, India

\section{Introduction}

India bears a heavy burden of type 2 diabetes. Recent data from the Global Burden of Disease Study showed that the overall

\footnotetext{
Lancashire Teaching Hospital, UK

2 Diabetacare, India
}

Address for correspondence: Dr Satyan M Rajbhandari Consultant Physician, Lancashire Teaching Hospital, Honorary Clinical Professor, University of Central Lancashire, Chorley \& South Ribble Hospital, Preston Road, Chorley PR7 1PP, UK

E-mail: satyan.rajbhandari@|thtr.nhs.uk

https://doi.org/10.15277/bjd.2020.259 adult (>20 years) prevalence of diabetes increased from $5.5 \%$ in 1990 to $7.7 \%$ in $2016 .{ }^{1}$ A large increase in population, from about 0.9 billion to about 1.3 billion during this period, ${ }^{2}$ masks the impact of this increase in prevalence on the healthcare system and society, as the number of adults with diabetes more than doubled from 26 million to 65 million.

Factors other than an increasing population have fuelled the growth in diabetes prevalence in India, however. People of South Asian heritage appear to have a distinct metabolic phenotype, characterised by a tendency towards abdominal obesity, higher insulin levels and a greater degree of insulin resistance compared with people of Caucasian heritage. ${ }^{3,4}$ These factors increase the susceptibility of people from (or descended from people from) the India subcontinent to developing type 2 diabetes and at a lower level of body mass index compared with Caucasian people. ${ }^{3,4}$ Urbanisation of the population has been a major feature of India's rapid economic development in recent years. ${ }^{5}$ This phenomenon is well known to contribute to a growth in the prevalence of diabetes and its complications, driven by increased access to high energy diets and reduced levels of physical activity, ${ }^{6}$ including in India. ${ }^{7-9}$ Increasing age is another risk factor for type 2 diabetes, ${ }^{10}$ and the average age of the population of India is increasing; the number of people aged $>65$ years increased from about 60 million in 2010 to about 90 million in 2020 and is projected to reach about 230 million by $2050 .{ }^{11}$

Data on the prevalence of dysglycaemia in defined regions of India are lacking, however, particularly with regard to its urban populations. We conducted a cross-sectional survey of the prevalence of diabetes and a measure of prediabetes in an urban population in Bangalore, India.

\section{Methods}

Screening was conducted free of charge and without need for a prior appointment on subjects who attended one of 32 screening sites throughout Bangalore, following local publicity in and around the sites conducted several days before screening took place. Demographic details, anthropometric measurements, blood pressure and information on dietary habits were collected in addition to measurements of capillary blood glucose. Diabetes was defined either on the basis of a self-reported prior diagnosis or as undiagnosed diabetes on the basis of a random blood glucose measurement $>11.1 \mathrm{mmol} / \mathrm{L}(200 \mathrm{mg} / \mathrm{dL}) .{ }^{12} \mathrm{~A}$ second index of dysglycaemia ('prediabetes') was defined as a random blood glucose measurement $>7.8 \mathrm{mmol} / \mathrm{L}(140 \mathrm{mg} / \mathrm{dL}$ ) but less than $11.1 \mathrm{mmol} / \mathrm{L} .{ }^{12}$ Subjects who did not meet these criteria were considered to have normal glucose regulation. 
Table 1 Proportions of subjects with different categories of glycaemic regulation

\begin{tabular}{llllll}
\hline Age category (years) & & & & \\
\hline $\mathbf{2 0 - 2 9}(\mathbf{n = 7 2 4 )}$ & $\mathbf{3 0 - 3 9}(\mathbf{n = 8 6 9 )}$ & $\mathbf{4 0 - 4 9}(\mathbf{n = 7 6 3 )}$ & $\mathbf{5 0 - 5 9 ( n = 6 8 3 )}$ & $\mathbf{6 0 - 6 9 ( n = 4 9 6 )}$ & $\mathbf{2 7 0}(\mathbf{n = 1 5 6 )}$ \\
$14(1.9 \%)$ & $80(9.2 \%)$ & $182(23.9 \%)$ & $251(36.8 \%)$ & $215(43.3 \%)$ & $76(48.7 \%)$ \\
$2(0.3 \%)$ & $9(1.0 \%)$ & $22(2.9 \%)$ & $18(2.6 \%)$ & $11(2.2 \%)$ & $5(3.2 \%)$ \\
$18(2.5 \%)$ & $50(5.8 \%)$ & $55(7.2 \%)$ & $58(8.5 \%)$ & $32(6.5 \%)$ & $8(5.1 \%)$ \\
$69(95.3 \%)$ & $730(84.0 \%)$ & $504(66.0 \%)$ & $356(52.1 \%)$ & $238(48 \%)$ & $67(43 \%)$
\end{tabular}

Data are $\mathrm{n}(\%)$. * Random glucose $>11.1 \mathrm{mmol} / \mathrm{L}$. ${ }^{\dagger}$ Random glucose $>7.8 \mathrm{mmol} / \mathrm{L}$. ${ }^{\ddagger}$ Random glucose $<7.8 \mathrm{mmol} / \mathrm{L}$ and no previous diabetes diagnosis.

Table 2 Dietary pattern and metabolic parameters of subjects taking a vegetarian and a non-vegetarian diet

\begin{tabular}{lll}
\hline Parameters & $\begin{array}{l}\text { Vegetarian } \\
\text { Mean (SD) }\end{array}$ & $\begin{array}{l}\text { Non-vegetarian } \\
\text { Mean (SD) }\end{array}$ \\
\hline Number & 744 & 943 \\
\hline Female, \% & $39.8 \%$ & $36.8 \%$ \\
\hline Age (years)* & $42.4(13.6)$ & $48.2(14.1)$ \\
BMI (kg/m²)* & $26(4.4)$ & $26.6(4.3)$ \\
\hline Systolic BP (mmHg) & $128(19.4)$ & $132.5(21.2)$ \\
\hline Diastolic BP (mmHg) & $78(35.2)$ & $77.7(12.3)$ \\
RBG (mmol/L)* & $6.3(2.0)$ & $7.8(4.1)$ \\
*P<0.05. BMl, body mass index; RBG, random capillary blood glucose.
\end{tabular}

\section{Results}

A total of 3,882 subjects were screened over a period of 15 months. Subjects aged $<20$ years $(n=31)$ and subjects with missing blood glucose data $(n=160)$ were excluded from analyses, leaving a final study population of 3,691 subjects.

About one-quarter of the population (22.1\%) reported a previous diagnosis of diabetes. Undiagnosed diabetes (random glucose $>11.1 \mathrm{mmol} / \mathrm{L}$ ) was found in $1.8 \%$, suggesting an overall diabetes prevalence of $23.9 \%$. The additional measure of prediabetes was found in 6\%. Overall, $30 \%$ had some form of diagnosed or undiagnosed abnormal glucose regulation. The remainder $(70 \%)$ had normal glycaemia by these criteria. Diabetes (diagnosed or undiagnosed) and prediabetes were more common in older subjects than in younger subjects (Table 1).

Dietary habits were available for 1,687 subjects; 744 were vegetarian and 943 were non-vegetarian. There were no significant differences between vegetarian and non-vegetarian subjects in mean blood pressure; however, non-vegetarians were older, had a higher body mass index and higher random capillary blood glucose (Table 2).

\section{Discussion}

Our findings suggest that diagnosed or undiagnosed diabetes is present in about one-quarter of urban residents of Bangalore and some form of abnormal glucose regulation is present in nearly one-third. Previous estimates of the prevalence of diabetes and prediabetes (defined as impaired fasting glucose (IFG) and/or impaired glucose tolerance (IGT)) in different regions of India have ranged from $2 \%$ to $16 \%$ and from $2 \%$ to $25 \%$, respectively. ${ }^{13-19}$ The high variation in these estimates likely results from differences in methodology, definitions and the nature of the populations studied (eg, urban vs rural), and it is difficult to compare these prevalence rates between studies. Nevertheless, our data appear to lie towards the higher end of these estimates and suggest the presence of a major burden of dysglycaemia among our urban Indian population.

The prevalence of any form of abnormal glucose regulation was higher in urban than in rural populations, consistent with the results of our study. 15,19,20 We found evidence of undiagnosed diabetes among our population (1.8\%), but at a much lower rate than that seen in other studies, which have detected a case of undiagnosed diabetes for about every two cases of diagnosed diabetes in India. ${ }^{15}$ This is likely due to the limited ability of our study to detect undiagnosed diabetes, as we had access to only a single random glucose measurement from subjects who attended our clinic spontaneously and without notice. Access to $\mathrm{HbA}_{1 \mathrm{c}}$ or fasting glucose measurements may have resulted in a higher prevalence of undiagnosed diabetes.

We found a significant association between non-vegetarian diet and raised body mass index. This is similar to other published studies. ${ }^{21}$ Subjects on a non-vegetarian diet were slightly older and had raised capillary blood glucose. The increasing popularity of a vegetarian diet in the younger generation could possibly explain this. The prevalence of abnormal glucose regulation increased with age, as would be expected. ${ }^{10}$ In our study, almost $50 \%$ of subjects above the age of 50 years had dysglycemia.

Our limited access to diagnostic measurements of blood glucose, as described above, was a major limitation of our study, as we were unable to measure $\mathrm{HbA}_{1 c}$ or blood glucose either in the fasting state or after an oral glucose tolerance test in order to formally diagnose the classical diabetes or prediabetic states of IFG or IGT. This limitation reflects the practical difficulty faced in conducting a large survey in a developing country. The elevated levels of blood glucose seen in our ambulatory subjects with prediabetes probably indicated that this subpopulation was enriched with people with IGT. In addition, we were unable to exclude people with IFG from our 'normoglycaemic' population. 


\section{Key messages}

- Diabetes and prediabetes are present in about a third of the urban adult ( $>20$ years) population of Bangalore, a major city in India

- One in 12 of the adult population have glucose abnormalities of which they are not aware

- Regular screening for diabetes and associated non-communicable diseases in urban areas should be considered by policy makers

Finally, our subjects volunteered to attend and were essentially a self-selected population. Our substantial survey population was the strength of this study.

In conclusion, we observed high rates of dysglycaemia in a large urban population in Bangalore. Our data add to previous reports of a substantial burden of abnormal glucose regulation in this setting. Weight loss is associated with biochemical remission and extended life expectancy for people with type 2 diabetes. ${ }^{22}$ This also prevents the development of diabetes in subjects with dysglycaemia. ${ }^{23}$ Additional public health initiatives are required to protect the citizens of Bangalore from diabetes and its future complications by making policy to discourage high sugar-containing foods and drinks and adapting the environment to enable weight loss in an urban population. A vegetarian diet could be encouraged by religious leaders to help this, but further studies are needed.

Acknowledgements We acknowledge the work of Diabetacare India staffs who helped in collecting this data. Dr Mike Gwilt, GT Communications, provided editorial assistance to the authors free of charge at the request of the British Journal of Diabetes.

Conflict of interest SMR, KVK, RS and TM had no potential conflicts of interest.

\section{Funding None.}

\section{References}

1. India State-Level Disease Burden Initiative Diabetes Collaborators. The increasing burden of diabetes and variations among the states of India: the Global Burden of Disease Study 1990-2016. Lancet Glob Health 2018;6:e1352-e1362. https://doi.org/10.1016/S2214-109X(18)30387-5

2. Worldometer. India population. Available at: https://www. worldometers.info/world-population/india-population/ (accessed March 2020).

3. Unnikrishnan R, Anjana RM, Mohan V. Diabetes in South Asians: is the phenotype different? Diabetes 2014;63:53-5. https://doi.org/10.2337/db131592

4. Sattar N, Gill JM. Type 2 diabetes in migrant south Asians: mechanisms, mitigation, and management. Lancet Diabetes Endocrinol 2015;3:100416. https://doi.org/10.1016/S2213-8587(15)00326-5

5. The World Bank. Urbanization in India. Available at: https://www.worldbank.org/en/news/feature/2011/09/22/india-urbanization (accessed March 2020).
6. Gassasse Z, Smith D, Finer S, Gallo V. Association between urbanisation and type 2 diabetes: an ecological study. BMJ Glob Health 2017;2:e000473. https://doi.org/10.1136/bmjgh-2017-000473

7. Kroll M, Bharucha E, Kraas F. Does rapid urbanization aggravate health disparities? Reflections on the epidemiological transition in Pune, India. Glob Health Action 2014;7:23447. https://doi.org/10.3402/gha.v7.23447

8. Kumar R, Singh MC, Singh MC, et al. Urbanization and coronary heart disease: a study of urban-rural differences in northern India. Indian Heart $J$ 2006;58:126-30.

9. Ramachandran A, Mary S, Yamuna A, Murugesan N, Snehalatha C. High prevalence of diabetes and cardiovascular risk factors associated with urbanization in India. Diabetes Care 2008;31:893-8. https://doi.org/ 10.2337/dc07-1207

10. Diabetes UK. The risk factors of type 2 diabetes. Available at: https://www.diabetes.org.uk/preventing-type-2-diabetes/diabetes-risk-factors (accessed March 2020).

11. World Health Organization. Global health and aging. Available at: https://www.who.int/ageing/publications/global_health.pdf (accessed March 2020).

12. American Diabetes Association. 2. Classification and diagnosis of diabetes: standards of medical care in diabetes-2020. Diabetes Care 2020;43(Suppl 1):S14-S31. https://doi.org/10.2337/dc20-S002

13. Ramachandran A, Snehalatha C, Kapur A, et al. High prevalence of diabetes and impaired glucose tolerance in India: National Urban Diabetes Survey. Diabetologia 2001;44:1094-101. https://doi.org/10.1007/s001250100627

14. Shah C, Sheth NR, Solanki B, Shah N. To assess the prevalence of impaired glucose tolerance and impaired fasting glucose in Western Indian population. J Assoc Physicians India 2013;61:179-84.

15. Anjana RM, Deepa M, Pradeepa R, et al. Prevalence of diabetes and prediabetes in 15 states of India: results from the ICMR-INDIAB population-based cross-sectional study. Lancet Diabetes Endocrinol 2017;5:585-96. https://doi.org/10.1016/S2213-8587(17)30174-2

16. Prasad DS, Kabir Z, Dash AK, Das BC. Prevalence and risk factors for diabetes and impaired glucose tolerance in Asian Indians: a community survey from urban eastern India. Diabetes Metab Syndr 2012;6:96-101. https://doi.org/10.1016/j.dsx.2012.05.016

17. Anjana RM, Pradeepa R, Deepa M, et al. Prevalence of diabetes and prediabetes (impaired fasting glucose and/or impaired glucose tolerance) in urban and rural India: phase I results of the Indian Council of Medical Research-INdia DIABetes (ICMR-INDIAB) study. Diabetologia 2011;54:30227. https://doi.org/10.1007/s00125-011-2291-5

18. Zargar AH, Wani AA, Laway BA, et al. Prevalence of diabetes mellitus and other abnormalities of glucose tolerance in young adults aged $20-40$ years in North India (Kashmir Valley). Diabetes Res Clin Pract 2008;82:276-81. https://doi.org/10.1016/j.diabres.2008.08.006

19. Sadikot SM, Nigam A, Das S, et al. The burden of diabetes and impaired glucose tolerance in India using the WHO 1999 criteria: prevalence of diabetes in India study (PODIS). Diabetes Res Clin Pract 2004;66:301-7. https://doi.org/10.1016/j.diabres.2004.04.008

20. Raghupathy $\mathrm{P}$, Antonisamy $\mathrm{B}$, Fall $\mathrm{CH}$, et al. High prevalence of glucose intolerance even among young adults in South India. Diabetes Res Clin Pract 2007;77:269-79. https://doi.org/10.1016/j.diabres.2006.12.005

21. Jin Y, Kanaya AM, Kandula NR, Rodriguez LA, Talegawkar SA. Vegetarian diets are associated with selected cardiometabolic risk factors among middle-older aged South Asians in the United States. J Nutr 2018;148:195460. https://doi.org/10.1093/jn/nxy217

22. Lean MEJ, Leslie WS, Barnes AC, et al. Two-year results of the randomised Diabetes Remission Clinical Trial (DiRECT). Durability of a primary care-led weight-management intervention for remission of type 2 diabetes: 2-year results of the DiRECT open-label, cluster-randomised trial. Lancet Diabetes Endocrino/ 2019;7:344-55. https://doi.org/10.1016/\$2213-8587(19)30068-3

23. Knowles WC, Barrett-Connor E, Fowler SE, et al, Diabetes Prevention Program Research Group. Reduction in the incidence of type 2 diabetes with lifestyle intervention or metformin. N Engl J Med 2002;346:393-403. https://doi.org/10.1056/NEJMoa012512 